\title{
Feeding difficulties and foregut dysmotility in Noonan's syndrome
}

\author{
N Shah, M Rodriguez, D St Louis, K Lindley, P J Milla
}

\begin{abstract}
Purpose-Noonan's syndrome is a common dysmorphic syndrome in which failure to thrive and gastrointestinal symptoms are frequent but poorly understood.

Design-Twenty five children with Noonan's syndrome were investigated by contrast radiology, $\mathrm{pH}$ monitoring, surface electrogastrography (EGG), and antroduodenal manometry (ADM).

Results-Sixteen had poor feeding and symptoms of gastrointestinal dysfunction. All 16 required tube feeding. Seven of 25 had symptoms of foregut dysmotility and gastro-oesophageal reflux. In the most symptomatic children (four of seven) EGG showed fasting frequency gradient loss along the stomach fundus and pylorus with antral postprandial frequency loss. ADM showed shortened fasting cycle length, with abnormal phase III and shortened postprandial activity containing phasic contractions.

Implications-Gastroduodenal motor activity was reminiscent of 32-35 week preterm patterns. The feeding difficulties appear to resolve as gut motility matures. In Noonan's syndrome, feeding problems appear to be the result of delayed gastrointestinal motor development.

(Arch Dis Child 1999;81:28-31)
\end{abstract}

Keywords: Noonan's syndrome; failure to thrive; foregut dysmotility; gastro-oesophageal reflux

Noonan and Ehmke in $1963^{1}$ first described a dysmorphic syndrome characterised by hypertelorism, a downward eyeslant, and low set posteriorly rotated ears. Other features include short stature, a short neck with webbing or redundancy of skin, cardiac anomalies, epicanthic folds, deafness, motor delay, and a bleeding diathesis. ${ }^{1-4}$

Severe feeding difficulties are common, yet often go unrecognised until it is obvious that the children are not thriving and have become malnourished. The prevalence and underlying cause are poorly understood, ${ }^{34}$ and the resolution of this problem poses great management difficulties for both the parents and the professionals involved in their care.

The origin of the feeding difficulties could involve a wide range of pathologies. ${ }^{5-7}$ However, symptoms suggestive of foregut dysmotility are common.

We studied a consecutive referral group of 25 children with Noonan's syndrome for the prevalence of feeding difficulties and gastro- intestinal symptoms. The most severely affected children were further investigated to assess the cause of their symptoms and feeding disorder.

\section{Patients}

The study population included 25 children (16 boys and nine girls; median age 3.2 years; range 2 months to 12 years) confirmed by a clinical geneticist to have Noonan's syndrome. Twenty of the children had congenital cardiovascular abnormalities including pulmonary stenosis and hypertrophic cardiomyopathy. ${ }^{4}$ Six infants had mothers who also had Noonan's syndrome (table 1).

The presence of feeding difficulties and gastrointestinal symptoms (vomiting, constipation, abdominal pain, and distension) was sought in all infants. Those children with the most severe clinical symptoms were investigated further. In eight patients, foregut motility was investigated by barium meal and follow through and 24 hour $\mathrm{pH}$ study. The children with the most severe symptoms were further investigated by surface electrogastrography (EGG) in five patients and antroduodenal manometry (ADM) in four of these five patients.

\section{Methods}

Antireflux and prokinetic medication was withdrawn for 48 hours before study and patients were fasted for at least four hours before our study. Patients undergoing ADM were fasted overnight.

INTRAOESOPHAGEAL pH MONITORING

Intraoesophageal $\mathrm{pH}$ monitoring was carried out for a period of 24 hours. An antimony monocrystant $\mathrm{pH}$ catheter was placed via the nose $5 \mathrm{~cm}$ above the lower oesophageal sphincter, confirmed by $x$ ray. A diary indicating the times of intake, position, and important events (such as vomiting) was recorded. The reflux index (per cent time spent with $\mathrm{pH}<4$ ), and duration of the longest episode were calculated. ${ }^{8}$ A four hour fast before commencement is standard, with the normal previously prescribed feed being given to each child.

SURFACE ELECTROGASTROGRAPHY

Gastric myoelectric activity was recorded from the gastric antrum, body, and fundus using our previously described method. ${ }^{9}$ Recordings were taken for one hour: 20 minutes fasting and 40 minutes after a test meal of Cow and Gate Premium $20 \mathrm{ml} / \mathrm{kg}$. The analogue signal was digitised and then underwent spectral analysis using an autoregressive modelling
Dr Shah.

Accepted 20 November 1998 
Table 1 Clinical features in Noonan's syndrome

\begin{tabular}{|c|c|c|c|c|c|}
\hline Patient & Sex & Age (years) & Gut symptoms & Foregut pathology & Cardiology diagnosis \\
\hline 1 & $\mathrm{~F}$ & 5 & None & - & $\mathrm{HC}$ \\
\hline 2 & $\mathrm{~F}$ & 3 & None & - & Normal \\
\hline 3 & $\mathrm{~F}$ & 0.03 & $\mathrm{PF}+\mathrm{C}$ & - & PS \\
\hline 4 & $\mathrm{~F}$ & 0.1 & $\mathrm{~V}$ & - & PS \\
\hline 5 & $\mathrm{~F}$ & 0.08 & $\mathrm{PF}+\mathrm{V}+\mathrm{Ab}$ pain, $\mathrm{D}+\mathrm{C}$ & GOR + malrotation & PS \\
\hline 6 & $\mathrm{~F}$ & 1 & $\mathrm{PF}$ & - & PS \\
\hline 7 & $\mathrm{~F}$ & 0.08 & $\mathrm{PF}$ & - & PS \\
\hline 8 & $\mathrm{~F}$ & 0.08 & $\mathrm{PF}+\mathrm{V}+\mathrm{Ab}$ pain, $\mathrm{D}+\mathrm{C}$ & GOR & Normal \\
\hline 9 & $\mathrm{M}$ & 8 & None & - & $\mathrm{HC}$ \\
\hline 10 & M & 4 & None & - & Normal \\
\hline 11 & $\mathrm{M}$ & 4 & None & - & Normal \\
\hline 12 & $\mathrm{M}$ & 8 & None & - & PS \\
\hline 13 & $\mathrm{M}$ & 1 & $\mathrm{PF}+\mathrm{V}+\mathrm{Ab}$ pain, $\mathrm{D}+\mathrm{C}$ & GOR & PS \\
\hline 14 & $\mathrm{M}$ & 3 & None & - & PS \\
\hline 15 & $\mathrm{M}$ & 11 & None & - & PS \\
\hline 16 & $M$ & 0.25 & $P F+V+C$ & - & PS \\
\hline 17 & M & 0.16 & $\mathrm{PF}+\mathrm{V}+\mathrm{Ab}$ pain, $\mathrm{D}+\mathrm{C}$ & GOR + malrotation & $\mathrm{HC}$ \\
\hline 18 & $\mathrm{M}$ & 0.08 & $\mathrm{PF}$ & - & $\mathrm{HC}$ \\
\hline 19 & $\mathrm{M}$ & 0.08 & $\mathrm{PF}+\mathrm{V}+\mathrm{Ab}$ pain, $\mathrm{D}+\mathrm{C}$ & GOR & PS \\
\hline 20 & M & 0.08 & $\mathrm{PF}+\mathrm{V}+\mathrm{Ab}$ pain, $\mathrm{D}+\mathrm{C}$ & GOR & PS \\
\hline 21 & $\mathrm{M}$ & 0.08 & $\mathrm{PF}$ & - & PS \\
\hline 22 & M & 0.33 & $\mathrm{PF}$ & - & Normal \\
\hline 23 & $\mathrm{M}$ & 1 & $\mathrm{~V}$ & - & $\mathrm{HC}$ \\
\hline 24 & $\mathrm{M}$ & 3 & None & - & $\mathrm{HC}$ \\
\hline 25 & $\mathrm{~F}$ & 1.5 & $\mathrm{PF}+\mathrm{V}+\mathrm{Ab}$ pain, $\mathrm{D}+\mathrm{C}$ & GOR & $\mathrm{HC}$ \\
\hline
\end{tabular}

^Age at presentation.

$\mathrm{PF}$, poor feeding; V, vomiting; D, abdominal distension; C, constipation; GOR, gastro-oesophageal reflux; Ab pain, abdominal pain; PS, pulmonary stenosis; HC, hypertrophic cardiomyopathy.

method to calculate the dominant frequency. Gastric antral electrical control activity frequency was considered normal if between $0.04-0.06 \mathrm{~Hz}$, (mean, $0.05 \mathrm{~Hz}$ ). Each channel was analysed separately during fasting and postprandial periods. Six age and sex matched control infants were extracted from a normative database of over 250 normal children with no gastrointestinal disease.

ANTRODUODENAL MANOMETRY

After an overnight fast a water perfused triple lumen manometric catheter $(0.6 \mathrm{~mm}$ inner and $2.5 \mathrm{~mm}$ outer diameter with ports at $5 \mathrm{~cm}$ intervals) was placed under fluoroscopic control with the tip at the duodenojejunal flexure. Fasting motor activity, if present, was recorded for a minimum of three cycles of the migrating motor complex, or four hours if not present. Phase III activity (characterised by regular rhythmic phasic activity with a frequency of 10-14 cycles/minute lasting longer than one minute) was assessed. The cycle length - that is, the intervals between successive episodes of phase III activity duration, motility index, and propagation velocity of the phase III activity front were measured. The length of postprandial activity was measured after a test meal of Cow and Gate Premium $20 \mathrm{ml} / \mathrm{kg} /$ body weight. Control manometric data were obtained from 10 aged matched children from our normative data.

STATISTICAL METHODS

Numerical values are presented as median and interquartile ranges. The Mann-Whitney U test was used for the frequency analysis of the EGG.

\section{Results}

SYMPTOMS

Poor feeding described as poor suck or refusal to drink or eat solids, and recurrent vomiting were present in 16 of 25 patients; all 16 required nasogastric feeding and three required placement of a feeding gastrostomy. In all three cases, the placement of the feeding gastrostomy was after investigations for foregut dysmotility. Eight of the 16 suffered from vomiting, abdominal pain, distension, and constipation.

BARIUM MEAL

Two of the 16 infants with gastrointestinal symptoms presented with midgut malrotation as demonstrated by barium meal, one was diagnosed in the neonatal period and the other during her first year, and both were associated with gastro-oesophageal reflux. Five had a hiatus hernia and were noted to reflux during the study with a poor stripping wave.

INTRAOESOPHAGEAL pH STUDIES

Eight of 16 infants with gastrointestinal symptoms had evidence of gastro-oesophageal reflux. In seven of eight this was demonstrated by $\mathrm{pH}$ study. The reflux index ranged from $9.9 \%$ to $19.75 \%$ (median, $10.2 \%$ ). All had acid reflux in both the upright and supine positions. Three had long reflux episodes ranging between 26 and 42 minutes (median, 37 minutes), indicative of poor acid clearance from the oesophagus. The other child (patient 17) had evidence of gastro-oesophageal reflux on barium meal in association with a midgut malrotation, and underwent laparotomy. The pH study was omitted.

\section{ELECTROGASTROGRAPHY}

Surface EGG from the children with Noonan's syndrome showed a slower frequency of electrical control activity in the gastric body but faster activity in the antrum, resulting in a loss of the normal aboral frequency gradient, which is similar to that described in children with cerebral palsy with foregut dysmotility. ${ }^{10}$ These data are shown in table 2.

Visual examination of the running spectral plots revealed that patients 5,20 , and 25 had 
Table 2 Electrogastrography (gastric antral electrical frequency) in five patients with Noonan's syndrome and controls

\begin{tabular}{|c|c|c|c|c|}
\hline & \multicolumn{2}{|c|}{ Fasting frequency (mean (interquartile range) $(\mathrm{Hz})$ ) } & \multicolumn{2}{|c|}{ Postprandial frequency (mean (interquartile range) (Hz)) } \\
\hline & Noonan's patients & Controls & Noonan's patients & Controls \\
\hline & 1) & & & 0.04 \\
\hline Channel 2 & $0.038(0.033-0.050)$ & $0.043(0.035-0.051) \mathrm{NS}$ & $0.038(0.026-0.047)$ & $0.047(0.041-0.053) \mathrm{p}<0.01$ \\
\hline Channel 3 & $0.036(0.025-0.042)$ & $0.043(0.035-0.048) \mathrm{p}<0.001$ & $0.034(0.023-0.045)$ & $0.045(0.039-0.053) \mathrm{p}<0.001$ \\
\hline Channel 4 & $0.05(0.042-0.054)$ & $0.037(0.031-0.051) \mathrm{p}<0.005$ & $0.048(0.041-0.060)$ & $0.045(0.035-0.053) \mathrm{p}<0.001$ \\
\hline
\end{tabular}

Table 3 Indices of motor function of the duodenum obtained from manometric recording in four patients with Noonan's syndrome and controls

\begin{tabular}{llllll}
\hline & $\begin{array}{l}\text { Cycle length } \\
\text { (minutes) }\end{array}$ & $\begin{array}{l}\text { Phasic activity } \\
\text { (minutes) }\end{array}$ & $\begin{array}{l}\text { Phasic activity MI } \\
\text { (Kpa/min) }\end{array}$ & $\begin{array}{l}\text { Non-propagation } \\
\text { (fraction) }\end{array}$ & $\begin{array}{l}\text { Postprandial activity } \\
\text { (minutes) }\end{array}$ \\
\hline $\begin{array}{l}\text { Patients } \\
\text { Patient 5 }\end{array}$ & 23.5 & 1.4 & 10.3 & $3 / 3$ & 45 \\
Patient 17 & 46.0 & 11.5 & 22.0 & $3 / 5$ & 68 \\
Patient 20 & 38.1 & 2.0 & 37.3 & $2 / 4$ & Test curtailed \\
Patient 25 & 40.1 & 2.3 & 26.6 & $1 / 4$ & 145 \\
Controls $(n=10)$ & 70 & 5.8 & 24.5 & $0 / 4$ & 90 \\
Median & 31.0 & 3.0 & 10.1 & - & 185 \\
Lower & 157.0 & 7.3 & 36.3 & & \\
Upper & & & & \\
\hline
\end{tabular}

^Patient 25 became distressed during this test, which was curtailed during the postprandial period.

no dominant frequency present, with disorganised electrical control activity, and patient 17 had a tachygastria.

Children with Noonan's syndrome also had a poor increase in spectral power in response to the standardised test meal. This is likely to result in delayed gastric emptying and hence exacerbate any tendency to gastro-oesophageal reflux.

ANTRODUODENAL MANOMETRY

The indices of motor activity from the four patients in whom ADM was carried out are shown in table 3 . The migrating motor complex was identified as a recurrent cycle of activity in which there was a period of intense regular phasic activity (phase III), preceded by irregular contraction (phase II). This cycle was disrupted by feeding and replaced by irregular segmenting activity (postprandrial activity).

Patients 5, 20, and 25 had no obvious phase III complexes in the fasting state but had bursts of clustered phasic activity in phase II; $70 \%$ of which were propagated aborally. Patient 17 had cyclical fasting activity present but the phase III activity was very long with slow propagation. In addition, clustered phasic activity was also present in phase II. In all patients in whom postprandial activity was measured, it was found to be shorter than controls and contained clusters of phasic activity, which were poorly propagated aborally. Patient 25 became distressed during the test, which was curtailed during the postprandial period.

\section{Discussion}

Feeding difficulties occur frequently but are often unrecognised and cause major management difficulties in Noonan's syndrome. However, the underlying aetiology is poorly understood. ${ }^{45}$

Gastro-oesophageal reflux occurs commonly in infants and young children and is a manifestation of an underlying foregut dysmotility. ${ }^{11}$ Gastro-oesophageal reflux may cause a variety of disorders including oesophagitis, aspiration pneumonia, and several feeding problems. In our series we found severe gastrointestinal symptoms in 16 of 25 patients. All had such poor feeding that they required nasogastric feeding and in three of these patients after completion of the investigations feeding gastrotomies were placed, although the presence of a feeding gastrostomy appears not to influence the investigations performed. ${ }^{7}$ Investigation of the most severely affected patients showed their poor feeding to be associated with gastro-oesophageal reflux and greatly impaired acid clearance, providing evidence of an underlying oesophageal dysmotility.

Fifty per cent of the subgroup of patients with Noonan's syndrome and severe gastrooesophageal reflux had evidence of motility problems affecting both the stomach and the upper small intestine and this is in keeping with previous results regarding gastric emptying and gastro-oesophageal reflux. ${ }^{12}$ Four of the five patients who underwent EGG had evidence of abnormal gastric myoelectrical activity (patient had 17 tachygastria; and patients 5, 20, and 25 had disorganised electrical control activity).

The patients with Noonan's syndrome in whom ADM was performed were also those patients who had abnormal myoelectrical activity on EGG. The contractile activity was immature rather than neuropathological in appearance, reminiscent of that seen in neonates of 32-35 weeks' gestation. ${ }^{9}{ }^{13}$

Normal intestinal motility is the result of the integration of complex control mechanisms arising in the myenteric plexus, muscle coats, and from the neurohumoral environment. Altered function of one of these factors might produce dramatic changes in motility. ${ }^{913} 14$ The severe gut motility problems that presented during infancy in our patients with Noonan's syndrome improved remarkably after 3 or 4 years of age. In addition, two patients (patients 5 and 17) had clinical characteristics compatible with a pseudo-obstructive syndrome, both of whom had malrotation of the midgut requiring surgery. These patients improved slowly, although now aged 3 and 5 years, respectively, they continue to have sporadic episodes of con- 
stipation without mechanical obstruction, which can be managed with senokot or lactulose. Patients 5 and 17 were similar to a group of patients with feeding problems after a Ladd's procedure for midgut malrotation described by Devane et $a l{ }^{7}$ some of whom had enteric neuropathies. Developmental delay is described as one of the features in this syndrome, ${ }^{34}$ and perhaps the delay in the development of the central nervous system is paralleled by delay in the development of the enteric nervous system. The similarity of the duodenal manometric recordings to those of preterm infants and the fact that all of our patients have improved with increasing age would support this notion. Thus, these patients with Noonan's syndrome with severe symptoms had a widespread intestinal dysmotility associated with their gastrooesophageal reflux, which is very likely to be caused by a global developmental delay of the enteric nervous system

The failure of recognition of feeding problems and gastro-oesophageal reflux in Noonan's syndrome leads to poor growth and nutrition. We recommend that in children with Noonan's syndrome who have feeding difficulties, investigations for the presence of gastrooesophageal reflux are undertaken early and treated with antireflux measures and, if appropriate, that tube feeding should be instituted.
1 Noonan JA, Ehmke DA. Associated non-cardiac malformations in children with congenital heart disease. $f$ Pediatr 1963;63:468-70

2 Robin M, Baraitser M. Multiple congenital anomalies, a diagnostic compendium. 1st ed. Champman and Hall Medical, 1991.

3 Sharland M, Burch M, Mckenna WM, Paton MA. A clinical study of Noonan syndrome. Arch Dis Child 1992;67:17883.

4 Noonan JA. Noonan syndrome. An update and review for the primary pediatrician. Clin Pediatr 1994;33:727-32.

5 Ravelli AM, Milla PJ. Detection of gastroesophageal reflux by electrical impedance tomography. $\mathcal{F}$ Pediatr Gastroenterol Nutr 1994;18:205-13.

6 Cates M, Billmire DF, Bull MJ, Grosfeld JL. Gastroesophageal dysfunction in Cornelia de Lange syndrome. 7 Pediatr Surg 1989;24:2648-50.

7 Devane SP, Coombes R, Smith VV, et al. Persistent gastrointestinal symptoms after correction of malrotation. Arch Dis Child 1992;67:218-21.

8 Richter JE, Castell DO. Gastroesophageal reflux: pathogenesis, diagnosis and therapy. Ann Intern Med 1982;97:93103.

9 Milla PJ. Intestinal motility during ontogeny and intestinal pseudo-obstruction in children. Pediatr Clin North Am 1996;43:511-32.

10 Reyes AL, Cash AJ, Green SH, Booth IW. Gastrooesophageal reflux in children with cerebral palsy. Child Care Health Dev 1993;19:109-18.

11 Hyman PE. Gastroesophageal reflux: one reason why baby won't eat. F Pediatr 1994;125:103-9.

12 Minami H, McCallum RW. The physiology and pathophysiology of gastric emptying in humans. Gastroenterology 1984;86:1592-610.

13 Ravelli AM, Aldermen SE, Bisset WM, Trompeter RS, Barrette TM, Milla PJ. Foregut motor function in chronic renal failure. Arch Dis Child 1992;67:1343-7.

14 Devane SP, Ravelli AM, Bisset WM, Smith VV, Lake BD, Milla PJ. Gastric antral dysrhyrthmias in children with chronic idiopathic intestinal pseudoobstruction. Gut 1992; 33: $1477-81$. 